\title{
Digital Master Builders: Disruptive Construction Technologies Philippe Block
}

Block Research Group, Institute of Technology in Architecture, ETH Zurich

block@arch.ethz.ch

\section{Introduction}

The United Nations Department of Economic and Social Affairs estimates that by 2050 the world's population will have increased by over 2.1 billion people (UN DESA, 2019). Providing housing and infrastructure for them would essentially require building an amount equivalent to what currently exists. It is simply not possible to build in the future the way we do today. To appropriately confront the urgency of the environmental crisis, the building industry faces three immediate challenges: 1) reducing pollution, particularly embodied carbon emissions; 2) slowing the depletion of natural resources; and 3) minimizing waste production. The first challenge refers foremost to embodied emissions (De Wolf et al., 2013, 2016, 2017). The second challenge asks for a reduction in the demand of material used by the building sector, since currently $40 \%$ of global resource consumption results in the disappearance of essential virgin materials (OECD, 2018). The third challenge centers on what is wasted during and after construction. In the European Union, $25-30 \%$ of all waste produced by humans comes from construction and demolition (EC, 2018).

\section{Strategies and Necessities for Change}

Based on the arguments above, it should be abundantly clear that we need to change the way we design and build structures and that collective efforts are required.

One sensible approach is to design structures with much longer life spans, which can resist a wider range of loads and can be used for multiple functions. The philosophy here is to avoid demolition and the associated end-of-life waste. For buildings to retain their value, they should be designed to be more flexible and adaptable to avoid obsolescence (Cheshire, 2016).

An alternative approach is to achieve improvements for the impact of construction by designing structures that use fewer materials, allow more sustainable materials and are easier to recycle (De Wolf et al., 2016). Such structures are lighter and can be more easily disassembled when obsolete. This approach, however, challenges engineers and architects to rethink the way structures are designed and to strive for more efficient, less wasteful construction methods.

This section presents a) the principles that allow the realization of this latter approach, as well as b) the tools that the Block Research Group (BRG) at ETH Zurich has developed in pursuit of feasible solutions for practice:

a) Strength through Geometry and Material Effectiveness

"Strength through Geometry" means achieving structural performance by harnessing the power of well-thought-out structural design. Efficient structural forms, such as shells or vaults, can significantly reduce the required structural volume by placing material only where needed, i.e. by following the flow of forces for all loading cases. In particular, the use of funicular (i.e. compression-only) forms can, even with reduced structural sections, also significantly reduce stress concentrations thanks to their ability to uniformly distribute the load across their section, furthermore enabling the use of weaker and thus more sustainable materials (Ashby, 2013; Habert \& Roussel, 2009).

Structural geometry also usually means a clearer understanding of the force-flow by the designer, who can thus separate compression and tension or strategically discretize the structure to control the structural behavior. This separation increases longevity and improves recyclability: easier access to the 
components to be corrected for corrosion, fire, etc. better facilitates their inspection and replacement, and single-material systems allow us to easily discern material for recycling at a structure's end of life.

However, the geometry of a structure cannot be separated from its materialization: specific structural forms are more congenial to or even require specific materials; that is, certain materials should be used with certain geometries. Usually, engineers focus on material efficiency; in doing so, they often forget "material effectiveness". In other words, structural design often centers on the idea of optimizing the amount of material (efficiency), sometimes without questioning if that material is the right one for that application (effectiveness). We need to use a material for what it is good for.

Concrete is a good example of this. Depending on loading and boundary conditions, large parts of reinforced concrete elements do not contribute to the performance of the structure and are just additional dead load. One could question if, for spanning elements working in bending, reinforced concrete is indeed the right material and if other materials or structural systems should be adopted.

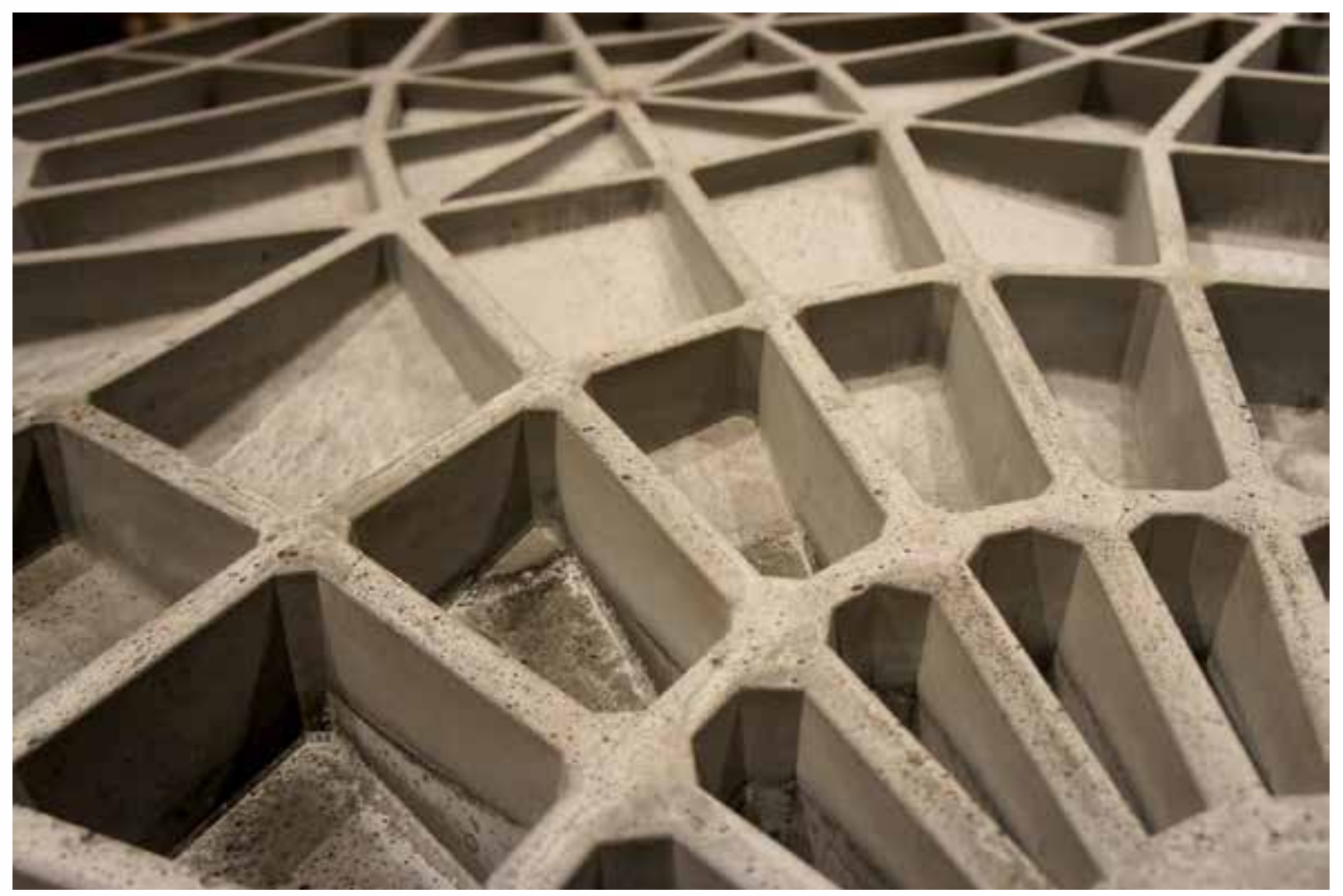

Figure 01: Mapungubwe Interpretive Centre, South Africa, 2008 and Rippmann Floor System prototype, 2016. The museum's tile vaults in soil-pressed tiles or the stiffened shell floor prototype are both thin, unreinforced structures using low-carbon-intensive material in very different contexts: soil-pressed tiles and concrete with a high percentage of recycled content. (Photos: Iwan Baan and Nick Krouwel)

\section{b) Computational Design and Digital Fabrication}

Achieving strength through geometry requires the structural designer to regain control of the geometry during the design process. Geometry is the universal language that connects the different fields of our industry, but in order to control it, traditional design tools are no longer sufficient, and new solutions are needed for both the design and analysis of structures. More importantly, the design process needs to change radically and to encapsulate structural constraints (and ideally many others, such as mechanical, fabrication, or construction constraints) from the start; the typical linear and iterative approach is no longer possible or even feasible!

Advanced analysis, design and drafting software are already available and in continuous development 


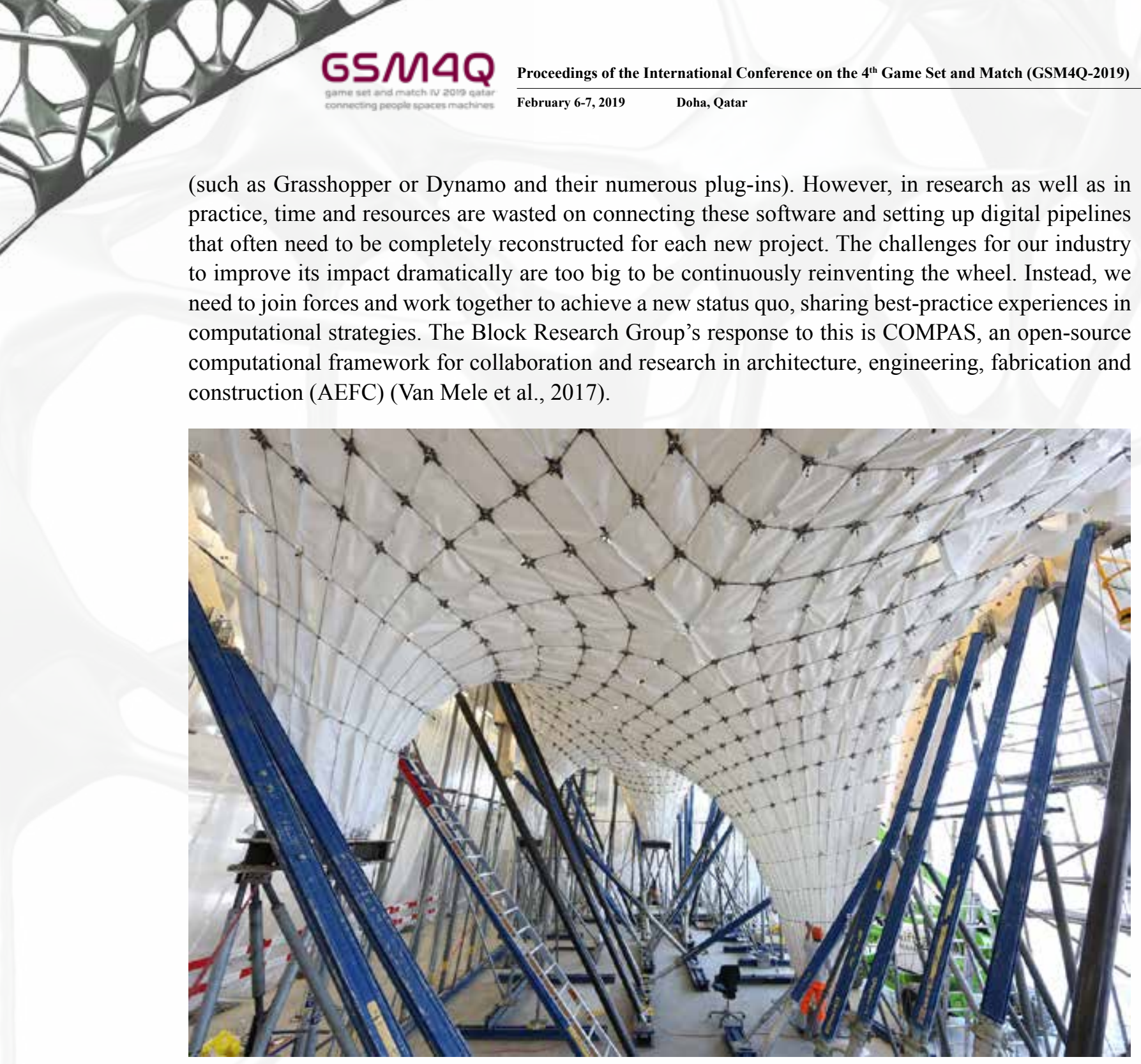

A: https://www.dropbox.com/s/3mio6snuk00jav2/HiLo_109_6J0A2753_Naida-Iljazovic.JPG?dl=0. 


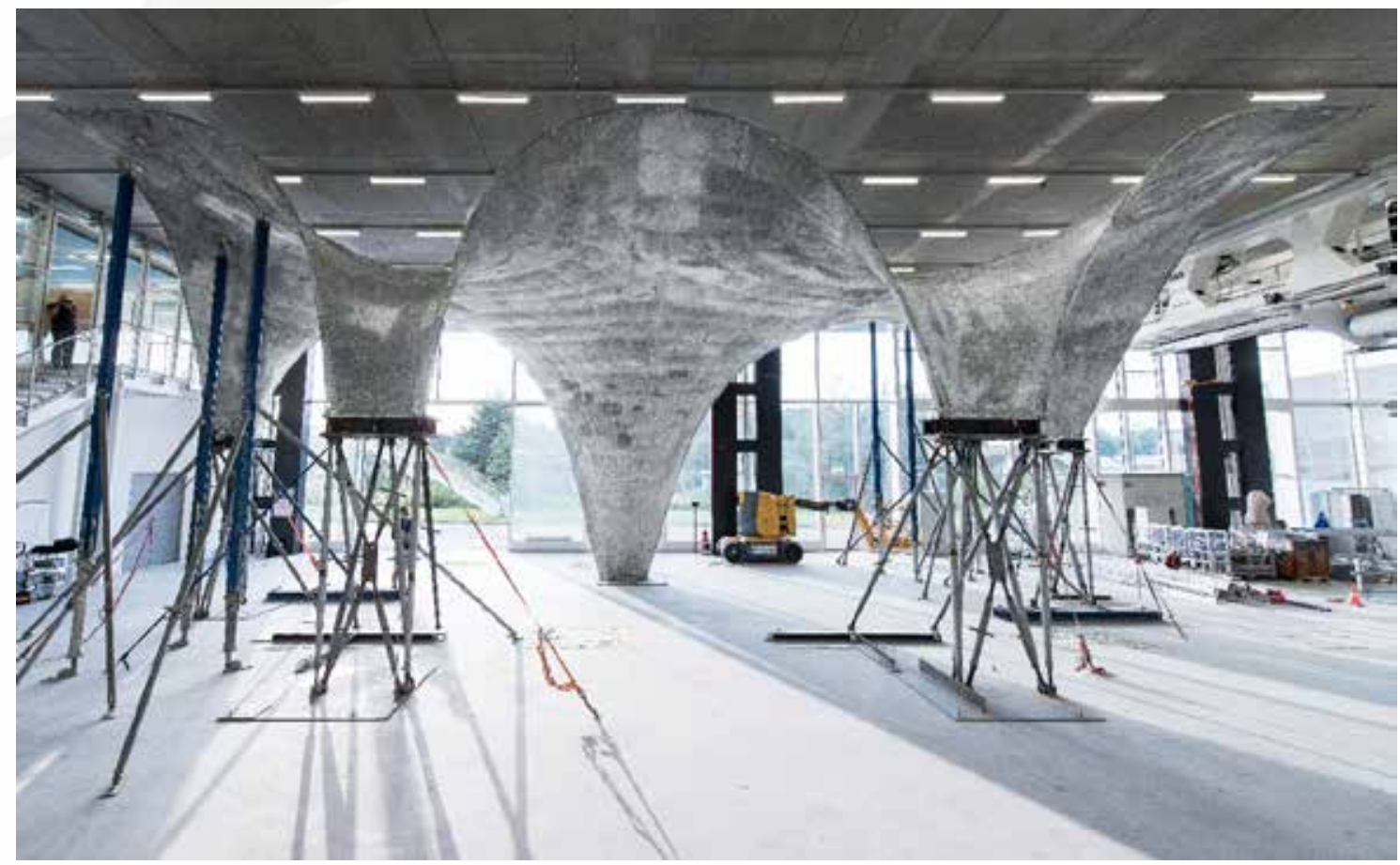

B: https://www.dropbox.com/s/ecdoj3gom20u74e/HiLo_003_DSC_0102_Michael-Lyrenmann.jpg?dl=0.

Figure 02: NEST HiLo concrete shell prototype, ETH Zurich, 2017. The extremely thin concrete shell was cast on a flexible, fully reusable formwork system, getting its efficiency through the use of a pre-stressed cable-net. (Photos: Naida Iljazovic and Michael Lyrenmann)

To facilitate the interaction and exchange between researchers and practitioners from various fields in the AEFC industry, and the adoption and integration of the tools, expertise and methods of their respective academic or professional communities, the computational core of COMPAS is designed to be entirely independent of CAD software and (FEA) analysis tools. It provides flexible and robust data structures, numerical solvers, geometry processing tools, topology algorithms, robotics fundamentals, extensive file format support and transparent wrapping mechanisms for state-of-the-art external libraries that can be used to tackle a wide variety of problems related to virtually every aspect of the modern AEFC development process. Furthermore, through a unified scripting API and flexible serialization and data persistence mechanisms, the core functionality of COMPAS can be easily and consistently implemented crossplatform, not only in tools such as Rhino, Grasshopper, and Blender but also in distributable standalone applications and even cloud-based web apps.

Architecture lags behind other industries not only on the computational side (McKinsey, 2015), but also on the fabrication side. The means and methods of today's construction industry are substantially similar to those applied more than one hundred years ago. This affects productivity, quality, and waste production, especially for non-standard structures, such as structurally optimized geometries that need more efficient shaping strategies for their realization. Typically, the production of complex building components is slow and wasteful, but opportunities exist in digital fabrication technology including full-scale 3D printing, robotic assembly, or 3D knitting that offer fast, versatile and less wasteful means of automated architectural production (Rippmann et al., 2018, 2019).

Digital fabrication not only improves precision and quality, but it can also enhance productivity and engagement of labor (Orr, 2019). The smart input of digital fabrication strategies simplifies logistics and makes building sites more efficient. It may also enhance work options and opportunities for workers, giving them more interesting, engaging or challenging tasks. 


\section{Conclusion}

As the gravity of warnings concerning global warming and the health of our planet increases, we can no longer ignore the building industry's contribution to the crisis, nor can we continue to build in the same way we have for the last $100+$ years, willfully ignoring the pollution and wastefulness caused by this model.

This short paper is meant as a 'call to action' for a better way of designing and building structures: we need to collectively work on new solutions to meet the environmental goals. Our architecture and structural engineering courses need to be revised to teach historic, often forgotten principles that value design acumen over material strength and to include more computation and digital fabrication skills. Our building codes need to change and equip engineers with tools to design more innovative structures.

The Block Research Group's research shows that when combined with the necessary computational and digital fabrication tools, principles like "strength through geometry" and "material effectiveness" can offer new opportunities to change our industry. However, many more strategies are needed for different contexts.

Finally, no change is possible if it is confined within the walls of a research institute and is not embraced by practitioners, contractors and developers. Whether it is for an iconic structure (such as a doubly curved, continuous shell roof) or one of the most common structural elements (such as a structural slab), architects, engineers, contractors, clients and developers, must investigate, adopt and promote more sustainable design choices. We have just about a decade to make a significant change! (IPCC, 2018).

\section{Note}

This paper is a summary of the paper by P. Block, T. Van Mele, M. Rippmann, F. Ranaudo, C. Calvo, and N. Paulson, "Redefining Structural Art: Strategies, necessities and opportunities", published in The Structural Engineer in January 2020. Through full-scale, built research demonstrators by the Block Research Group at ETH Zurich, this essay presents strategies, based on advances in computational structural design and digital fabrication, to take on these challenges, offering opportunities for a necessary disruptive change.

\section{References}

Ashby (2013); Habert, G. and Roussel, N. (2009). Study of two concrete mix-design strategies to reach carbon mitigation objectives. Cement and Concrete Composites, 31: 6: 397-402.

Cheshire, D. (2016). Building Revolutions: Applying the Circular Economy to the Built Environment. RIBA publishing.

De Wolf, C. (2017). Low Carbon Pathways for Structural Design: Embodied Life Cycle Impacts of Building Structures. (PhD Thesis). Retrieved from Massachusetts Institute of Technology.

De Wolf, C., Ramage, M., \& Ochsendorf, J. (2016). Low Carbon Vaulted Masonry Structure. Journal of the International Association for Shell and Spatial Structures, 57(4), 275.

embodied emissions in buildings - A review of current trends. Energy and Buildings, 66: 232-245.

European Commission. (2018). Construction and Demolition Waste (CDW). Retrieved from http://ec.europa.eu/ environment/waste/construction_demolition.htm and Resource Efficient Use of Mixed Wastes, http://ec.europa.eu/ environment/waste/studies/mixed_waste.htm. Accessed on February 28, 2020.

Ibn-Mohammed, T., Greenough, R., Taylor, S., Ozawa-Meida, L., \& Acquaye, A. (2013). Operational vs

IPCC. (2018). Global Warming of 1.5C. An IPCC Special Report on the impacts of global warming of $1.5^{\circ} \mathrm{C}$ above preindustrial levels and related global greenhouse gas emission pathways, in the context of strengthening the global response to the threat of climate change, sustainable development, and efforts to eradicate poverty. 
McKinsey Global Institute. (2015). Digital America: A Tale of the Haves and Have-Mores: Executive Summary. McKinsey\&Company, 5. www.mckinsey.com/industries/technology-media-and-telecommunications/our-insights/ digital-america-a-tale-of-the-haves-and-have-mores (Accessed November 2019).

OECD. (2018). Global Material Resources Outlook to 2060: Economic Drivers and Environmental Consequences. OECD Publishing, Paris.

Orr, J., Drewniok, M., Walker, I., Ibell, T., Copping, A., \& Emmitt, S. (2019). Minimizing energy in construction: Practitioners' views on material efficiency. Resources, Conservation and Recycling, 140: 125-136.

Orr, J., Pronk, A., \& Ibell, T. (2019). Editorial Special Issue: Advanced Manufacturing and Materials for Innovative Structural Design. Structures, 18: 1.

Popescu, M., Reiter, L., Liew, A., Van Mele, T., Flatt, R. J., \& Block, P. (2018). Building in concrete with a knitted stay-in-place formwork: Prototype of a concrete shell bridge. Structures, 14: 322-332.

Rippmann, M., Liew, A., Van Mele, T., \& Block, P. (2018). Design, fabrication and testing of discrete 3D sand-printed floor prototypes. Materials Today Communications, 15: 25-259.

Thoma A., Adel, A., Helmreich, M., Wehrle, T., Gramazio, F., \& Kohler, M. (2019) Robotic Fabrication of Bespoke Timber Frame Modules. Robotic Fabrication in Architecture, Art and Design 2018. ROBARCH 2018 (Springer, Cham)

United Nations Department of Economic and Social Affairs. (2019). World Population Prospects 2019. Retrieved from https://population.un.org/wpp/. Accessed on February 28, 2020.

Van Mele, T. et al. (2017) COMPAS. Retrieved from https://compas-dev.github.io/. Accessed on February 28, 2020. 